\title{
Knowledge, Attitude and Practice of Patients with Diabetes Regarding Eye Care: A Cross Sectional Study
}

\author{
Eberechukwu Ogbeanu Achigbu1 ${ }^{*}$, Reginald Nnamdi Oputa², Kingsley Ihedioha Achigbu ${ }^{3}$, \\ Ikenna Ugochukwu Ahuche ${ }^{1}$ \\ ${ }^{1}$ Department of Ophthalmology, Federal Medical Centre, Owerri, Nigeria \\ ${ }^{2}$ Department of Medicine, Federal Medical Centre, Owerri, Nigeria \\ ${ }^{3}$ Department of Paediatrics, Federal Medical Centre, Owerri, Nigeria \\ Email: "ebyachigbu1@gmail.com
}

Received 31 October 2015; accepted 9 May 2016; published 12 May 2016

Copyright (C) 2016 by authors and Scientific Research Publishing Inc.

This work is licensed under the Creative Commons Attribution International License (CC BY). http://creativecommons.org/licenses/by/4.0/

cC) (7) Open Access

\begin{abstract}
Introduction: The non-communicable eye diseases such as diabetic retinopathy have become significant threats to vision and require lifelong management. The development of ocular complications of diabetes has been associated with longstanding and/or poorly controlled disease. Early detection and prevention are keys to reduce this scourge, but this largely depends on the existing knowledge. Objective: This study is aimed at determining the knowledge, attitude and practice regarding eye care among patients living with diabetes with a view to making recommendations for a multidisciplinary patient-centered approach to ophthalmic care. Methods: One hundred and three respondents were interviewed using a structured questionnaire in a cross sectional study carried out in the Endocrinology Clinic of Federal Medical Centre, Owerri, Imo State, Nigeria. Results: There was a female preponderance with a male to female ratio of $1: 1.3$. Of these respondents, $68.9 \%$ had been diabetic for 5 years or less; $56.4 \%$ could define diabetes; but only $40.77 \%$ could mention some ocular complications of diabetes. Only $31.1 \%$ had had their eyes examined; the rest had not been to an eye clinic due to lack of funds, time, no ocular problems and not having been referred to an eye doctor. This attitude and practice were not significantly associated with age, sex, occupation or duration of illness. Conclusion: Though more than half of the respondents could define diabetes, there is still a poor knowledge of the ocular complications of diabetes and a poor attitude and practice regarding eye care among these patients. An interdisciplinary patient-centred approach to the management of diabetic eye diseases is recommended so as to reduce the burden of visual impairment from diabetes.
\end{abstract}

${ }^{*}$ Corresponding author.

How to cite this paper: Achigbu, E.O., Oputa, R.N., Achigbu, K.I. and Ahuche, I.U. (2016) Knowledge, Attitude and Practice of Patients with Diabetes Regarding Eye Care: A Cross Sectional Study. Open Journal of Ophthalmology, 6, 94-102. 


\section{Keywords}

Diabetes, Knowledge, Impact, Eye, Management

\section{Introduction}

The non-communicable chronic eye diseases-diabetic retinopathy (DR), glaucoma, and age related macular degeneration (AMD) are incurable, require lifelong management and have become significant threats to vision with ageing [1]. The demographic (people living longer) and epidemiological (changing diets and lifestyle) transitions have been implicated as direct causes especially for DR and AMD [1]. Diabetic retinopathy usually occurs following a long standing and/or poorly controlled disease with hypertension and lipid disorders as co-morbidities.

Eighty percent of people with diabetes live in low and middle income countries [2]. In Nigeria 3.2 million (2.4\%) Nigerians have diabetes and only about $20 \%$ of them are aware of it [3]. This implies that many people may be living with complications of diabetes and these may have socio-economic implications.

The well-known complications of diabetes include cataract which is 2 - 5 times more likely to occur in diabetics and also more likely to occur earlier [4]. Diabetic retinopathy is the most common cause of visual loss among people with diabetes and the leading cause of visual impairment and blindness among working-age adults [4]. It may be complicated by diabetic maculopathy. DR usually occurs in longstanding diabetes or poorly controlled diabetes due to vascular changes as a result of chronic high blood sugar [4].

In spite of the availability of technology which aids early detection of DR in the developed countries, prevention and management are still emphasized [1].

In poor resource countries such as Nigeria, prevention and management are very crucial. But this largely depends on the knowledge the patients possess, the effect of this knowledge on their psyche and their attitude towards eye care. Some studies have reported poor knowledge of diabetes and its risk factors [5], while in others despite a high level of knowledge, work was still needed to change the health behavior [6]. Racial differences were noted in other studies [7].

This study is aimed at assessing the knowledge people with diabetes and attending the endocrinology clinic of Federal Medical Centre Owerri, Imo State have, the attitudinal effect of this knowledge and their practice regarding eye care.

This is with a view to making recommendations to the health authorities and the diabetic society of Nigeria on how to create awareness and educate the society on the ocular complications of diabetes, its prevention and management using an interdisciplinary patient-centred approach.

\section{Subjects and Methods}

\subsection{Study Area}

This study was carried out in the Endocrinology Clinic of the Department of Internal Medicine, Federal Medical Centre, Owerri, Imo state, Nigeria.

\subsection{Study Design}

A cross sectional study was carried out using a structured questionnaire. The questionnaire captured information on the demographic data of the respondents, their medical history, knowledge of diabetes and its complications, their attitude and practice regarding diabetic eye care.

\subsection{Subjects}

It includes all previously diagnosed patients (prior to the study period) with diabetes who attended the Clinic during the period of the study in 2013.

\subsection{Data Collection}

Data was collected using a questionnaire administered by the interviewer. The questionnaire was divided into 
five parts:

1) Section A: Demographic data of the subjects including their age, sex, and occupation.

2) Section B: The medical history of the subjects.

3) Section C: Duration and knowledge of patient's illness and complications.

4) Section D: Consisted of questions about the subject's attitude and practice regarding diabetic eye care.

\subsection{Data Analysis}

Data collected was analysed using the SPSS version 20 (2012) and presented in tables and charts. The chi square statistical tool was used in the analysis of the result. A P value of $<0.05$ was considered statistically significant.

\subsection{Ethical Considerations}

Consent was obtained from the Federal Medical Centre Ethics committee, while informed verbal consent was obtained from the subjects who participated in the study.

\section{Results}

One hundred and three subjects consisting of 44 males and 59 females with a ratio of 1:1.3 participated in the study.

Most (51.5\%) of the respondents were in the 51 - 60 years age range. They were predominantly dependents (41.7\%) followed by those who earned their living doing some form of business.

Majority (68.9\%) had been diabetic for 5 years or less. The rest 22.3\%, $4.9 \%$ and 3.9\% respectively had been diabetic for 6 - 10 years, 11 - 15 years and 16 - 20 years.

A little over half of the respondents (56.3\%) knew diabetes was excess sugar in the blood, 37.9\% didn't know what diabetes is while, $4.9 \%$ and $1.0 \%$ respectively of the respondents thought it is caused by hypertension and pregnancy.

At a $\mathrm{P}$ value of 0.000 , the relationship between age and knowledge of diabetes was statistically significant.

There was however no significant relationship between knowledge of diabetes and sex $(\mathrm{P}=0.175)$ or occupation $(\mathrm{P}=0.513)$. There is also no positive relationship with the duration of diabetes $(0.419)$.

Seventy two (69.9\%) respondents correctly noted that diabetes can affect the eyes. However, only 42 (40.77\%) of the respondents mentioned complications of diabetes. The complications noted were cataract by 12 (11.65\%) respondents and blindness by 30 (29.12\%) respondents.

This knowledge was not significantly associated with age (0.481), sex (0.742), occupation (0.643), and the duration of diabetes (0.526).

Only 32 (31.1\%) had had their eyes examined. Of these, only 2 (1.9\%) had never seen an eye doctor. Having the eyes examined was significantly associated with age (0.04) but not with sex $(0.17)$, occupation $(0.27)$, the knowledge they possessed (0.42) and the duration of illness (0.10).

\section{Discussion}

There were more female participants in this study as in other similar studies with some reporting a higher prevalence of diabetes among females. in contrast to others [5] [6] [8]-[13].

Majority of the participants as shown in Table 1 were above 50 years in keeping with known knowledge and had been diabetic for 5 years or less. This is similar to findings in other studies [6] [9] but contrary to the findings in the study done among Saudi women [14].

Approximately $42 \%$ of the respondents were dependents being catered for by other members of their family followed by those involved in some type of business (29.1\%) (Table 1). Similarly in the study carried out in Kenya, 30\% were sit at home parents while $22.1 \%$ and $3.2 \%$ respectively of the respondents in a study in Karachi were housewives and unemployed citizens [8] [10].

Majority of the participants were diagnosed diabetic within the past 5 years including the $5^{\text {th }}$ year as at the time of the study. This is contrary to the study in South India where about half $30.04 \%$ of the respondents had been diabetic for less than 5 years [9]. The difference may be because the latter study was a community based study.

Regarding the knowledge of diabetes (Table 2), slightly over half (56.4\%) of the respondents defined diabetes 
Table 1. Demographic data of the 103 respondents.

\begin{tabular}{cccc}
\hline Variable & & Frequency (N) & Percentage (\%) \\
\hline \multirow{2}{*}{ Age (years) } & $20-30$ & 2 & 1.9 \\
& $31-40$ & 3 & 2.9 \\
& $41-50$ & 16 & 15.5 \\
& $51-60$ & 53 & 51.5 \\
& $61-70$ & 26 & 25.2 \\
Sex & $71-80$ & 3 & 2.9 \\
\hline \multirow{2}{*}{ Occupation } & Male & 44 & 42.7 \\
& Female & 59 & 57.3 \\
\hline & Civil servant & 12 & 11.7 \\
& Dependants & 43 & 41.7 \\
& Business & 30 & 29.1 \\
\hline
\end{tabular}

Table 2. The Knowledge of diabetes among the respondents.

\begin{tabular}{|c|c|c|c|c|c|c|}
\hline \multicolumn{7}{|c|}{ Cause of Diabetes } \\
\hline & & Don’t know (\%) & Sugar in blood \% & High blood pressure & Pregnancy & Total \\
\hline \multirow{6}{*}{ Age } & 20 - 30 years & $0(0)$ & $1(1.7)$ & $1(20)$ & $0(0)$ & $2(1.9)$ \\
\hline & 31 - 40 years & $0(0)$ & $2(3.4)$ & $0(0)$ & $1(100)$ & $3(2.9)$ \\
\hline & 41 - 50 years & $4(10.3)$ & $10(17.2)$ & $2(40)$ & $0(0)$ & $16(15.5)$ \\
\hline & 51 - 60 years & $24(61.5)$ & $28(48.3)$ & $1(20)$ & $0(0)$ & $53(51.5)$ \\
\hline & $61-70$ years & $10(25.6)$ & 15 (25.9) & $1(20)$ & $0(0)$ & $26(25.2)$ \\
\hline & 71 - 80 years & $1(2.6)$ & $2(3.40$ & $0(0)$ & $0(0)$ & $3(2.9)$ \\
\hline \multirow{2}{*}{ Sex } & Male & $12(30.8)$ & $30(51.7)$ & $2(40)$ & $0(0)$ & $44(42.7)$ \\
\hline & Female & $27(69.2)$ & $28(48.3)$ & $3(60)$ & $1(100)$ & $59(57.3)$ \\
\hline \multirow{5}{*}{ Occupation } & Civil servant & $3(7.7)$ & $7(12.1)$ & $1(20)$ & $1(100)$ & $12(11.7)$ \\
\hline & Student/Dependant & 19 (48.7) & $22(37.9)$ & $2(40)$ & $0(0)$ & $43(41.7)$ \\
\hline & Business & $9(23.1)$ & $19(32.8)$ & $2(40)$ & $0(0)$ & $30(29.1)$ \\
\hline & Artisans & $2(5.1)$ & $2(3.4)$ & $0(0)$ & $0(0)$ & $4(3.9)$ \\
\hline & Farmers & $6(15.4)$ & $8(13.8)$ & $0(0)$ & $0(0)$ & $14(13.6)$ \\
\hline \multirow{4}{*}{ Duration } & 1 - 5 years & $29(74.4)$ & $39(67.2)$ & $2(40)$ & $1(100)$ & 71 (68.9) \\
\hline & $6-10$ years & $5(12.8)$ & $16(27.6)$ & $2(40)$ & $0(0)$ & $23(22.3)$ \\
\hline & 11 - 15 years & $2(5.1)$ & $2(3.4)$ & $1(20)$ & $0(0)$ & $5(4.9)$ \\
\hline & 16 - 20 years & $3(7.7)$ & $1(1.7)$ & $0(0)$ & $0(0)$ & $4(3.9)$ \\
\hline
\end{tabular}

as excess sugar in the blood. This means that $43.6 \%$ of the respondents didn't know what diabetes is. This is comparable with the result from other studies with $35.2 \%$ and $48.12 \%$ having no knowledge of diabetes, and 40.3\% not able to score above $10 \%$ in the series of knowledge questions among Saudi women [8] [14] [15].

In contrast, $38.5 \%$ of respondents in the South Indian study could define diabetes but this low figure may be attributed to the fact that this question also assessed the knowledge of the types of diabetes [9].

The knowledge of diabetes as shown in Table 3 was significantly correlated with age in this study. This finding is similar to the findings in other studies [6] [8]. In Omani age, duration of diabetes (5 - 10 years) and the region where the respondents reside positively influenced their knowledge [6]. However unlike their study, duration of illness and other variables did not positively influence our respondents' knowledge. 
Table 3. Analysis of knowledge of diabetes with the socio-demographic variables.

\begin{tabular}{|c|c|c|c|c|}
\hline \multicolumn{5}{|c|}{ Knowledge of diabetes } \\
\hline & & N (\%) & Chi-square & (p value) \\
\hline \multirow{6}{*}{ Age } & $20-30$ years & $2(1.9)$ & \multirow{6}{*}{48.71} & \multirow{6}{*}{$(0.000)$} \\
\hline & 31 - 40 years & $3(2.9)$ & & \\
\hline & 41 - 50 years & $16(15.5)$ & & \\
\hline & 51 - 60 years & $53(51.5)$ & & \\
\hline & $61-70$ years & $26(25.2)$ & & \\
\hline & 71 - 80 years & $3(2.9)$ & & \\
\hline \multirow{2}{*}{ Sex } & Male & 44 (42.9) & \multirow{2}{*}{4.96} & \multirow{2}{*}{$(0.18)$} \\
\hline & Female & 59 (57.3) & & \\
\hline \multirow{5}{*}{ Occupation } & Civil servant & $12(11.7)$ & \multirow{5}{*}{11.18} & \multirow{5}{*}{$(0.51)$} \\
\hline & Student/Dependant & 43 (41.7) & & \\
\hline & Business & 30 (29.1) & & \\
\hline & Artisans & $4(3.9)$ & & \\
\hline & Farmers & 14 (13.6) & & \\
\hline \multirow{4}{*}{ Duration } & 1 - 5 years & 71 (68.9) & \multirow{4}{*}{9.20} & \multirow{4}{*}{$(0.42)$} \\
\hline & 6 - 10 years & $23(22.3)$ & & \\
\hline & $11-15$ years & $5(4.9)$ & & \\
\hline & $16-20$ years & $4(3.9)$ & & \\
\hline
\end{tabular}

In the south Indian study [9], age had no correlation with the knowledge score of the participants. In addition duration of diabetes also had no positive effect on their knowledge similar to our study.

The ocular complications noted in this study were cataract and blindness. These were noted by $40.77 \%$ of the respondents with only $11.65 \%$ aware of cataract as a complication of diabetes. While $29.12 \%$ reported that diabetes could cause blindness, it can be inferred that the pathways to blindness from diabetes which includes cataract and diabetic retinopathy were not common knowledge among these respondents living with diabetes. as there was sadly, no mention of refractive error and diabetic retinopathy as complications of diabetes

In Ghana [16], a low knowledge was reported among the respondents with none of them showing any knowledge regarding cataract and diabetic retinopathy as ocular complications of diabetes. Fifteen (3.8\%) respondents however noted that ocular refraction can be affected by diabetes unlike our study. In another study that specifically assessed the knowledge of diabetes and diabetic retinopathy in a rural population, only $37 \%$ had knowledge about diabetic retinopathy [17].

Approximately $60 \%$ of our respondents (Table 4) therefore had no knowledge of the effect of diabetes in the eyes with the study in Karachi showing a similar result (63.7\%) [8]. Much higher figures were noted in another study (90.5\%) [17].

Almost double the number of our respondents (72.9\%) showed excellent knowledge concerning the ocular complications of diabetes in Omani [6]. In Kenya, 83\% of the participants had heard of diabetic eye disease and $60 \%$ of these knew the relationship between diabetic eye disease and diabetes [10].

Literacy and being in the upper and middle socio economic class have been noted to influence the knowledge of diseases [18]-[20]. In developing countries such as Nigeria, the emphasis of health care is mostly clinical with little attention paid to health education, promotion and prevention. These may account for these results. Moreover our study showed that most of the respondents were dependents that may not have access to the plethora of information on diabetes in the internet.

The knowledge of the ocular complications of diabetes as shown in Table 5 was not significantly associated age, sex, occupation or duration of diabetes in our study similar to other studies [9]. In contrast, other studies found higher level of education, higher social class, age ( $>45$ years) and Christianity as factors that influenced the knowledge of the respondents while others noted a higher female preponderance associated with knowledge [8] [10] [17]. The difference in methodology of these studies may account for these differences. 
Table 4. Analysis of knowledge of diabetes affecting the eyes with the socio-demographic variables.

\begin{tabular}{|c|c|c|c|c|}
\hline \multicolumn{5}{|c|}{ Do you know that diabetes can affect the eye } \\
\hline & & $\mathrm{N}(\%)$ & Chi-square & (p value) \\
\hline \multirow{6}{*}{ Age } & 20 - 30 years & 2 (1.9) & \multirow{6}{*}{10.70} & \multirow{6}{*}{$(0.06)$} \\
\hline & 31 - 40 years & $3(2.9)$ & & \\
\hline & 41 - 50 years & $16(15.5)$ & & \\
\hline & 51 - 60 years & 53 (51.5) & & \\
\hline & $61-70$ years & $26(25.2)$ & & \\
\hline & 71 - 80 years & $3(2.9)$ & & \\
\hline \multirow{2}{*}{ Sex } & Male & 44 (42.7) & \multirow{2}{*}{0.11} & \multirow{2}{*}{$(0.74)$} \\
\hline & Female & $59(57.3)$ & & \\
\hline \multirow{5}{*}{ Occupation } & Civil servant & 12 (11.7) & \multirow{5}{*}{2.51} & \multirow{5}{*}{$(0.64)$} \\
\hline & Student/Dependant & $43(41.7)$ & & \\
\hline & Business & 30 (29.1) & & \\
\hline & Artisans & $4(3.9)$ & & \\
\hline & Farmers & $14(13.6)$ & & \\
\hline \multirow{4}{*}{ Duration } & 1 - 5 years & $71(68.9)$ & \multirow{4}{*}{2.23} & \multirow{4}{*}{$(0.53)$} \\
\hline & 6 - 10 years & 23 (22.3) & & \\
\hline & 11 - 15 years & $5(4.9)$ & & \\
\hline & 16 - 20 years & $4(3.9)$ & & \\
\hline
\end{tabular}

Table 5. Analysis of eye examination with the socio-demographic variables.

\begin{tabular}{|c|c|c|c|c|}
\hline \multicolumn{5}{|c|}{ Have you ever had your eyes examined } \\
\hline & & N (\%) & Chi-square & (p value) \\
\hline \multirow{6}{*}{ Age } & 20 - 30 years & $2(1.9)$ & \multirow{6}{*}{11.81} & \multirow{6}{*}{$(0.04)$} \\
\hline & 31 - 40 years & $3(2.9)$ & & \\
\hline & 41 - 50 years & $16(15.5)$ & & \\
\hline & 51 - 60 years & $53(51.5)$ & & \\
\hline & 61 - 70 years & $26(25.2)$ & & \\
\hline & 71 - 80 years & $3(2.9)$ & & \\
\hline \multirow{2}{*}{ Sex } & Male & 44 (42.7) & \multirow{2}{*}{1.88} & \multirow{2}{*}{$(0.17)$} \\
\hline & Female & $59(57.3)$ & & \\
\hline \multirow{5}{*}{ Occupation } & Civil servant & $12(11.7)$ & \multirow{5}{*}{5.13} & \multirow{5}{*}{$(0.27)$} \\
\hline & Student/Dependant & $43(41.7)$ & & \\
\hline & Business & $30(29.1)$ & & \\
\hline & Artisans & $4(3.9)$ & & \\
\hline & Farmers & $14(13.6)$ & & \\
\hline \multirow{4}{*}{ Duration } & 1 - 5 years & 71 (68.9) & \multirow{4}{*}{6.18} & \multirow{4}{*}{$(0.10)$} \\
\hline & $6-10$ years & $23(22.3)$ & & \\
\hline & 11 - 15 years & $5(4.9)$ & & \\
\hline & 16 - 20 years & 4 (3.9) & & \\
\hline
\end{tabular}

Regular ocular examination is a necessary requirement in order to curb the increasing visual impairment associated with chronic non communicable diseases such as diabetes. However, very few of the respondents have imbibed this habit irrespective of their age, sex, occupation, duration of illness and the knowledge they possess. 
This is reflected in the poor practice of eye care among these individuals because only $31.1 \%$ of the respondents had had their eyes examined. Of these, the majority (11: 36.6\%) had been to the eye clinic two times with the duration of ill health as the only significant influencing variable (Figure 1).

This poor attitude and practice depicted in Figure 2 were attributed to factors such as lack of funds, very busy schedules with no time to attend eye clinics, the absence of visual impairment, and the fact that they have not been asked to see an eye doctor. This behavior is a reflection of the deficit in knowledge of these patients who believe that they should attend an eye clinic only when they develop symptoms. It is also an insight into how much work needs to be done by the health practitioners in bridging the gap and educating the general public and particularly those living with diabetes on when to see an ophthalmologist.

The study in Kenya reported that $50 \%$ of their 30 participants went for eye check and 53\% already had visual problems [10]. Among those who went for ocular examination, $27 \%$ went once in a year, $10 \%$ twice a year and

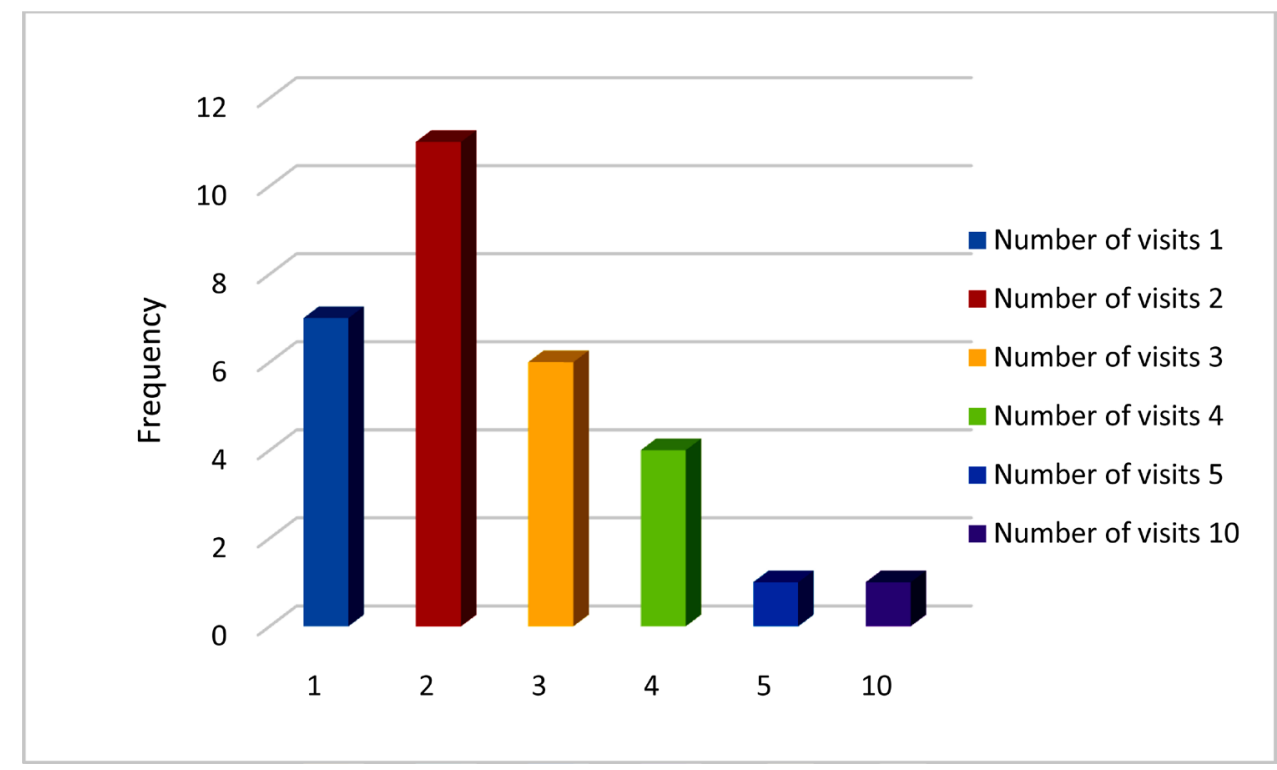

Majority of the respondents visited an eye clinic twice.

Two of those who had visited the eye clinic didn't indicate the number of visits.

The duration of diabetes $(\mathrm{P}=0.025)$ was significantly associated with the number of hospital visitations while age (0.792), sex (0.373) and occupation (0.053) were not positively related to it.

\section{Figure 1. A bar chart showing number of visitations to the eye clinic.}

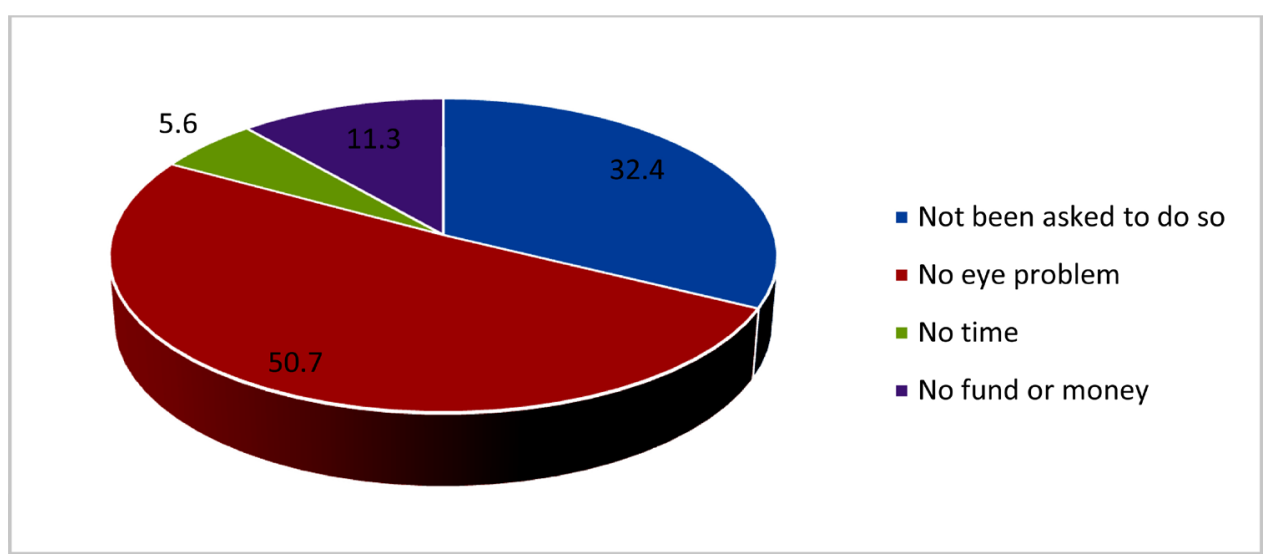

Majority (50.7\%) of the respondents did not have their eyes examined because they didn't have any eye problems (symptoms). This was followed closely by $32.4 \%$ who felt they needed to be referred by their physician before getting their eyes examined.

Age (0.415), Sex (0.95), Occupation (0.57), and duration of diabetes (0.28) did not significantly influence this practice.

Figure 2. A pie chart showing reasons for not going for ocular examination. 
$17 \%$ monthly. The visit to the hospital may also have been influenced by the ocular disorders.

Interestingly, $56.8 \%$ of respondents in another study saw an ophthalmologist while $9.2 \%$ asked for retinal examination [8]. The study also reported that $58.8 \%$ recognized the role of the ophthalmologists in screening for diabetic retinopathy. For over half of the study population to visit an ophthalmologist is a reflection of the level of knowledge of the disease available and utilized by this group of people.

The ophthalmologists have a role to play in driving the education and enlightenment of the general public and people living with diabetes about diabetes, its complications, management modalities, where and when to go for screening. This can be achieved in collaboration with the physicians and the ministry of health.

\section{Conclusions}

More than half of the respondents could define diabetes but there was poor knowledge of the complications of diabetes with none of them mentioning refractive error and diabetic retinopathy as possible complications.

There is also a poor attitude and practice to the uptake of eye care in spite of the knowledge of diabetes as a cause of blindness.

\section{Recommendation}

The health ministry in collaboration with health educators can plan programmes targeted at educating and changing the attitudes of the public and people living with diabetes regarding eye care.

\section{Limitations of the Study}

The study did not assess the knowledge of the treatment modalities for diabetic eye disease and the effect of education on the knowledge and attitude of the respondents.

This study was carried out in a clinic setting; it may therefore not be a true reflection of the knowledge attitude and practice of the general populace. A larger community based study is recommended.

\section{References}

[1] Resnikoff, S. and Kocur, I. (2014) Non-Communicable Eye Diseases: Facing the Future. Community Eye Health Journal, 27, 41-43.

[2] IDF (2013) International Diabetes Atlas. 6th Edition. http://www.idf.org/sites/default/files/EN_6E_Atlas_Full_0.pdf

[3] Oputa, R.N. (2009) National Diabetes Screening Programmes. Diabetes International, 17, 9-11.

[4] National Eye Institute (2015) Facts about Diabetic Eye Disease. https://nei.nih.gov/health/diabetic/retinopathy

[5] Islam, F.M.A., Chakrabarti, R., Dirani, M., Islam, M.T., Ormsby, G., et al. (2014) Knowledge, Attitudes and Practice of Diabetes in Rural Bangladesh: The Bangladesh Population Based Diabetes and Eye Study (BPDES). PLoS ONE, 9, e110368. http://dx.doi.org/10.1371/journal.pone.0110368

[6] Khandekar, R., Al Harby, S., Al Harthy, H. and Al Lawatti, J. (2010) Knowledge, Attitude and Practice Regarding Eye Complications and Care among Omani Persons with Diabetes-A Cross Sectional Study. Oman Journal of Ophthalmology, 3, 60-65. http://dx.doi.org/10.4103/0974-620X.64228

[7] Pardhan, S. and Mahomed, I. (2004) Knowledge, Self-Help and Socioeconomic Factors in South Asian and Caucasian Diabetic Patients. Eye (London), 18, 509-513. http://dx.doi.org/10.1038/sj.eye.6700680

[8] Memon, M.S., Shaikh, S.A., Shaikh, A.R., Fahim, M.F., Mumtaz, S.N. and Ahmed, N. (2015) An Assessment of Knowledge, Attitude and Practices (KAP) towards Diabetes and Diabetic Retinopathy in a Suburban Town of Karachi. Pakistan Journal of Medical Sciences, 31, 183-188.

[9] Hawal, N.P., Shivaswamy, M.S., Sanjay, K., Shweta, P. and Hiremath, M.B. (2012) Knowledge, Attitude and Behaviour Regarding Self-Care Practices among Type 2 Diabetes Mellitus Patients Residing in an Urban Area of South India. International Multidisciplinary Research Journal, 2, 31-35.

[10] Mwangi, M.W., Githinji, G.G. and Githinji, F.W. (2011) Knowledge and Awareness of Diabetic Retinopathy amongst Diabetic Patients in Kenyatta National Hospital. Kenya International Journal of Humanities and Social Science, 1, $140-146$.

[11] Ekpenyong, C.E., Akpan, U.P., Ibu, J.O. and Nyebuk, D.E. (2012) Gender and Age Specific Prevalence and Associated Risk Factors of Type 2 Diabetes Mellitus in Uyo Metropolis, Southeastern Nigeria. Diabetologia Croatica, 41, 17-23.

[12] Ramachandran, A., Snehalatha, C., Kapur, A., et al. (2001) High Prevalence of Diabetes and Impaired Glucose Toler- 
ance in India: National Urban Diabetes Survey. Diabetologia, 44, 1094-1101. http://dx.doi.org/10.1007/s001250100627

[13] Basavanagowdappa, H., Prabhakar, A.K., Prasannaraj, P., Gurudev, K.C. and Virupaksha, S. (2005) Study of Prevalence of Diabetes Mellitus and Impaired Fasting Glucose in a Rural Population. International Journal of Diabetes in Developing Countries, 25, 98-101. http://dx.doi.org/10.4103/0973-3930.27012

[14] Saadia, Z., Rushdi, S., Alsheha, M., Saeed, H. and Rajab, M. (2009) A Study of Knowledge Attitude and Practices of Saudi Women towards Diabetes Mellitus. A (KAP) Study in Al-Qassim Region. The Internet Journal of Health, 11.

[15] Jiskani, A., Qidwai, U. and Riaz, Q. (2013) Knowledge, Attitude, Prevalence (KAP) Regarding Diabetes and Diabetic Retinopathy (DR): A Study of Gaddap Town Karachi. Ophthalmology Update, 11, 212-214.

[16] Ovenseri-Ogbomo, G.O., Abokyi, S., Koffuor, G.A. and Abokyi, E. (2013) Knowledge of Diabetes and Its Associated Ocular Manifestations by Diabetic Patients: A Study at Korle-Bu Teaching Hospital, Ghana. Nigerian Medical Journal, 54, 217-223. http://dx.doi.org/10.4103/0300-1652.119602

[17] Rani, P.K., Raman, R., Subramani, S., Perumal, G., Kumaramanickavel, G. and Sharma, T. (2008) Knowledge of Diabetes and Diabetic Retinopathy among Rural Populations in India, and the Influence of Knowledge of Diabetic Retinopathy on Attitude and Practice. Rural and Remote Health, 8, 838. http://www.rrh.org.au

[18] Williams, M.V., Baker, D.W., Parker, R.M. and Nurss, J.R. (1998) Relationship of Functional Health Literacy to Patients' Knowledge of Their Chronic Disease. A Study of Patients with Hypertension and Diabetes. Archives of Internal Medicine, 158, 166-172. http://dx.doi.org/10.1001/archinte.158.2.166

[19] Rothman, R.L., Malone, R. and Bryant, B. (2005) The Spoken Knowledge in Low Literacy in Diabetes Scale. The Diabetes Educator, 31, 215-224. http://dx.doi.org/10.1177/0145721705275002

[20] Dandona, R., Dandona, L., John, R.K., McCarty, C.A. and Rao, G.N. (2001) Awareness of Eye Diseases in an Urban Population in Southern India. Bulletin of the World Health Organisation, 79, 96-102. 